\title{
Gibi Digital: uma atividade de matemática desenvolvida cooperativamente no espaço do Facebook
}

\author{
Aline Silva De Bona - vivaexatas@yahoo.com.br \\ Marcus Vinicius de Azevedo Basso - mbasso@ufrgs.br \\ Léa da Cruz Fagundes - leafagun@ufrgs.br
}

Resumo: O artigo é o relato de uma atividade de matemática proposta no espaço de aprendizagem digital escolhido pelos estudantes, do IFRS - Campus Osório, como o Facebook, em 2012. A atividade tem a finalidade de mobilizar os estudantes a demonstrar o que aprenderam sobre os conceitos de geometria espacial. A metodologia de trabalho docente com os estudantes é dialogada de Freire, e o método de análise dos gibis é à luz da Teoria de Piaget, onde esta atividade é parte de uma pesquisa-ação de doutoramento. O objetivo do artigo é apontar atividades interessantes aos estudantes, sendo estas extraclasse e alicerçadas na tecnologias digitais, online e/ou não, onde ocorrem a aprendizagem cooperativa dos conceitos de matemática tão usualmente citados em avaliações externas. Dentre os resultados desta atividade cita-se a escrita dos conceitos de geometria espacial de acordo com suas palavras e o destaque dados pelos estudantes aos gibis como recursos para estudar.

Palavras-chaves: Tecnologias Digitais, Atividade de Matemática, Espaço de Aprendizagem Digital, Aprendizagem Cooperativa.

\section{Digital Comics: a cooperatively developed mathematical activity in the space Facebook}

\begin{abstract}
The article is the result of a math activity proposed in the digital learning space chosen by the students of IFRS - Campus Osorio, like Facebook, in 2012. The activity aims to mobilize students to demonstrate what they have learned about the concepts of spatial geometry. The teaching methodology is dialogued with students of Freire, and the method of analysis of comics is the Theory of Piaget, where this activity is part of an action research $\mathrm{PhD}$. The objective of this article is to point out interesting activities for students, which are grounded in extracurricular and digital technologies, online and / or does not, occur where cooperative learning of math concepts commonly cited as external. Among the results of this activity refers to the writing of the concepts of spatial geometry according to his words and emphasis given by students to comic books as resources for study.
\end{abstract}

Keywords: Digital Technologies, Math Activity, Space Digital Learning, Cooperative Learning.

\section{Introdução}

É de notório saber que as atividades de matemática são geralmente as mesmas em todas as aulas, por mais que se estude e se diversifiquem as propostas de sala de aula, geralmente todas as aulas de matemática contemplam listas de exercícios ou 
problemas sobre os conceitos trabalhados em cada aula. Além disso, muitas vezes quando os professores de matemática desejam propor dinâmicas diferentes, baseadas em atividades não usuais, os estudantes lamentam e perguntam: "Quando a professora vai dizer a fórmula e como se faz este exercício? Fica enrolando", segundo um estudante de 15 anos do IFRS - Campus Osório. Assim, fica evidente que cada vez mais é importante demonstrar aos estudantes o objetivo das atividades "diferentes" e fazer com que estes possam sugerir formas, que lhe sejam interessantes, para demonstrar o que: sabem, pesquisaram, e aprenderam de matemática, além de explorar recursos que lhe agradam como as tecnologias digitais, online ou não. Sendo esta a questão central do artigo: Como propor atividades diferentes de matemática de forma que os estudantes se mobilizem a aprender os conceitos desta área do conhecimento, e não somente desejem aplicar sem sentido algum?

Com o objetivo de mobilizar os estudantes a aprender a aprender matemática busca-se meios como: o uso do espaço de aprendizagem digital da matemática, de Bona, Fagundes (2011), escolhido por esta turma a rede social Facebook, a aprendizagem cooperativa, de Piaget (1973) e Bona, Fagundes, Basso (2012b), proporcionada pela intermediação das tecnologias digitais online, e a diversidade de atividades, onde se destaca a atividade dos gibis. Esta atividade foi proposta pela professora de matemática durante o $2^{\circ}$ trimestre de 2012, aos estudantes do $2^{\circ}$ ano do Ensino Médio Integrado em Informática do IFRS - Campus Osório, contemplando os conceitos de Geometria Espacial. Ao propor a atividade aos estudantes estes de imediato solicitaram a professora se poderia ser realizada em trios e de forma online, no Facebook, explorando qualquer tecnologia para criação do gibi. Aponta-se neste momento que o objetivo da atividade é que cada um ou trio demonstre com suas palavras o que aprenderam de matemática sobre o assunto geometria espacial.

Além disso, um estudante neste dia, no turno da tarde, manifesta-se no espaço de aprendizagem digital - Facebook da turma com uma postagem urgente: "A lógica é cada um fazer como quer e postar no Facebook da turma para que possamos ler e debater, dai a sora olha e faz pergunta como sempre. Todos lendo de todos vamos deixando a história redondinha e correta de matemática, né? ah tb acho que não podemos repetir softwares e sites free de edição de gibis para não ficar chato o visual..."

De acordo com a postagem do estudante, que foi curtida por todos os seus colegas em menos de 2 horas, pode-se constatar que as tecnologias digitais online estão presentes na vida escolar e a necessidade de troca de ideias entre os estudantes também se faz presente como forma de aprender, além da natural apropriação do espaço de aprendizagem digital da Matemática - Facebook. Implícita na necessidade de troca de ideias destaca pelo estudante está a aprendizagem cooperativa, pois no seu comentário não ocorrerá apenas uma socialização dos gibis, mas, também, um momento de debate entre os estudantes e neste a professora pode participar com perguntas.

Portanto, o objetivo do artigo é apontar atividades interessantes aos estudantes, sendo estas extraclasse e alicerçadas na tecnologias digitais, online e/ou não, onde ocorrem a aprendizagem cooperativa dos conceitos de matemática tão usualmente citados em avaliações externas, como Prova Brasil, ENEM, e outras, quanto se trata particularmente de geometria. Entende-se como atividade todo o seu contexto, ou seja, desde seu planejamento docente, a forma que é proposta aos estudantes, a concepção docente, até a sua avaliação formativa e somativa.

No relato desta atividade estão contemplados o ambiente de sala de aula online que é o espaço de aprendizagem digital da matemática escolhido pelos estudantes como a rede social Facebook, a forma de conceber a aprendizagem dos estudantes neste espaço que é a aprendizagem cooperativa, ancorada na Teoria de Piaget, os conteúdos 
que devem ser explorados pelos pelos estudantes no gibi e também que estes serão avaliados tanto pela construção do gibi, no âmbito da matemática como da tecnologia digital, como no resultado final, que é avaliado pelos estudantes no "debate" e pela professora com "perguntas".

Para Fiorentini e Lorenzato (2007), é evidente que cada vez mais atividades como esta relatada neste artigo se fazem necessárias para melhorar a educação matemática no Brasil, pois dizer que matemática é importante, assim como as tecnologias digitais também são, todos já sabem a questão central é esta de dizer como através de exemplos e experiências bem sucedidas na escola básica.

O artigo está organizado pela: introdução, espaço de aprendizagem digital e a aprendizagem cooperativa, atividade do gibi digital, resultados e considerações finais, referências bibliográficas.

\section{Espaço de Aprendizagem Digital e a Aprendizagem Cooperativa}

Primeiramente se faz necessário definir os dois conceitos - espaço de aprendizagem digital da matemática e aprendizagem cooperativa - que dão estrutura e suporte para esta atividade dos gibis digitais, pois estas são realizadas extraclasse e sob uma metodologia dialogada com a professora de matemática, de Freire (1999).

Espaço de Aprendizagem Digital da Matemática "é um local não situado geograficamente onde o processo de ensino-aprendizagem ocorre através da organização e aplicação de uma concepção pedagógica, baseada na comunicação, interação, trabalho colaborativo do professor com os estudantes, e cooperativos dos estudantes entre si e com o professor", segundo Bona, Fagundes, Basso (2011, p.2).

Este 'espaço' é adotado como um recurso, e nesta concepção se insere as interfaces digitais, porque a interface digital é composta de um ambiente de aprendizagem informatizado que contemplam: links de softwares livres e de applets, hipertextos autodirigidos, espaços de chats e trocas de experiências, vídeos explicativos e outros elementos digitais. Tais elementos compõem o 'espaço' e são essenciais à criação da necessidade de se aprender Matemática. Para Peters (2009), este 'espaço' entendido como recurso é um ambiente de aprendizagem de grande potencial e pouco explorado hoje, porque o foco tem de ser a autoaprendizagem individual e coletiva.

O espaço de aprendizagem digital da matemática adotado por cada turma e este é variado, pode ser desde um blog coletivo (pbworks, wikizoo, blogs, baboo), até uma rede social, como Facebook. Atualmente, o 'espaço' mais adotado pelos estudantes é a rede social Facebook, segundo Bona, Fagundes e Basso (2012e), tanto para matemática como para outras disciplinas, como séries e cursos, devido, essencialmente, a sua funcionalidade (a maioria das pessoas já conhecem o ambiente e sabem "mexer") e fácil acesso em qualquer internet 3G. Não é o objetivo deste artigo apontar os motivos da escolha dos estudantes para este espaço, mas estes estão disponíveis em Bona, Fagundes e Basso (2012c).

Ao trabalhar - pesquisar com o conceito de espaço de aprendizagem digital da matemática, desde 2012, na escola básica, em 2011, insere-se as ideias de colaboração e cooperação de Piaget (1973). Assim, conclui-se, em 2011 e 2012, que a aprendizagem cooperativa é potencializada pelas tecnologias digitais online, e que neste 'espaço' ela proporciona o processo de construção dos conceitos de matemática, segundo Bona, Fagundes, Basso (2012d,c e b).

A aprendizagem está alicerçada na ação do estudantes, ou seja, nas suas interações. Em Piaget (1973), as interações são definidas como sendo ações se 
modificando umas as outras, conforme determinadas leis de organização ou de equilíbrio. Segundo ele, além dos fatores orgânicos, que condicionam do interior os mecanismos da ação, toda conduta supõe duas espécies de interações que a modificam de fora e são indissociáveis uma da outra.

Há, portanto, a interação entre o sujeito e os objetos e a interação entre o sujeito e outros sujeitos. É desse modo que a relação entre o sujeito e o objeto modifica o sujeito e o objeto ao mesmo tempo, porque ocorre assimilação de um ao outro e a acomodação do sujeito ao objeto. Esse processo acontece em todo trabalho coletivo humano, pois cada relação social constitui uma totalidade nela mesma, capaz de criar características novas que transformam o indivíduo em sua estrutura mental.

A partir da interação entre dois indivíduos surge uma totalidade que é constituída pelo conjunto das relações interindividuais de uma mesma sociedade. Esta totalidade não constitui a soma dos indivíduos, nem a soma de uma realidade superposta aos indivíduos, mas a de um sistema de interações modificando os sujeitos em sua própria estrutura.

O conhecimento humano é essencialmente coletivo, e a vida social constitui um dos fatores essenciais da formação e do crescimento dos conhecimentos pré-científicos e científicos. Tais conhecimentos não partem nem do sujeito nem do objeto, mas da interação indissociável entre eles, para avançar a partir deste ponto na dupla direção de uma exteriorização objetivante e de uma interiorização reflexiva.

Assim, “[...] cooperar na ação é operar em comum, isto é, ajustar por meio de novas operações (qualitativas ou métricas) de correspondências, reciprocidade ou complementaridade, as operações executadas por cada um dos parceiros" (PIAGET, 1973, p.105), e "colaborar, entretanto, resume-se à reunião das ações que são realizadas isoladamente pelos parceiros, mesmo quando o fazem na direção de um objetivo comum" (PIAGET, 1973, p.105). Portanto, a aprendizagem cooperativa é um método de ação dos estudantes para a aprender a aprender, e também uma concepção de prática docente adotada pela professora, onde nesta a avaliação é parte do processo e é essencialmente formativa.

Desta forma, a aprendizagem cooperativa não é potencializada devido ao fato de cada estudante ter seu espaço, ou, quando coletivo, fica difícil identificar cada ação do estudante aos mesmos e ao professor; assim como em algumas redes sociais é complicado de trabalhar - como o Orkut, devido a postagem ser em cada mural e não na sequência do grupo, mas quando ocorrem estas interações pela 'operação em comum'.

No entanto, apenas o Facebook também não possibilita o 'operar em comum', para isto é necessário integrar a prática docente do contrato didático ou disciplinar para que o método de ação do Facebook possibilite a aprendizagem cooperativa, sendo este conceito de contrato didático implícito a aprendizagem cooperativa, pois segundo Piaget (1973), para se cooperar é necessário a existência de regras autônomas de condutas fundamentadas no respeito mútuo entre todos os sujeitos.

Então, o Facebook é um espaço de aprendizagem digital da matemática onde é possível aprender a aprender por cooperação, segundo a pesquisa-ação de doutoramento de um dos autores deste artigo, e neste contexto o tipo de atividade proposta para ser realizada neste espaço é fundamental, inclusive, como neste artigo apontado os gibis digitais.

\section{Atividade do Gibi Digital}

A atividade foi proposta, no $2^{\circ}$ trimestre, aos estudantes do $2^{\circ}$ ano do Ensino 
Médio Integrado em Informática do IFRS - Campus Osório, em 2012, pela professora de matemática, uma das autoras deste artigo. O objetivo da atividade é mobilizar os estudantes a aprender a aprender matemática, e paralelamente realizar uma avaliação formativa sobre os conceitos de matemática sobre geometria espacial até então trabalhados tanto em sala de aula presencial como no espaço de aprendizagem digital da matemática o Facebook.

A questão proposta aos estudantes com esta atividade foi: Construir um gibi que explique o que aprendeu de geometria espacial de forma livre e criativa. Como dito na introdução por iniciativa de um estudante a atividade passou a ser em trios e com recursos digitais diversos como exemplos, os mais usados: Tumblr, Memebase, Twitter, Bitstrips, aplicativos do Facebook, e vídeos feitos em versão animada postados no You Tube. A seguir, as figuras 1, 2 e 3 exemplificam o layout dos gibis digitais construídos respectivamente, no Memebase, Tumblr, e Bitstrips.

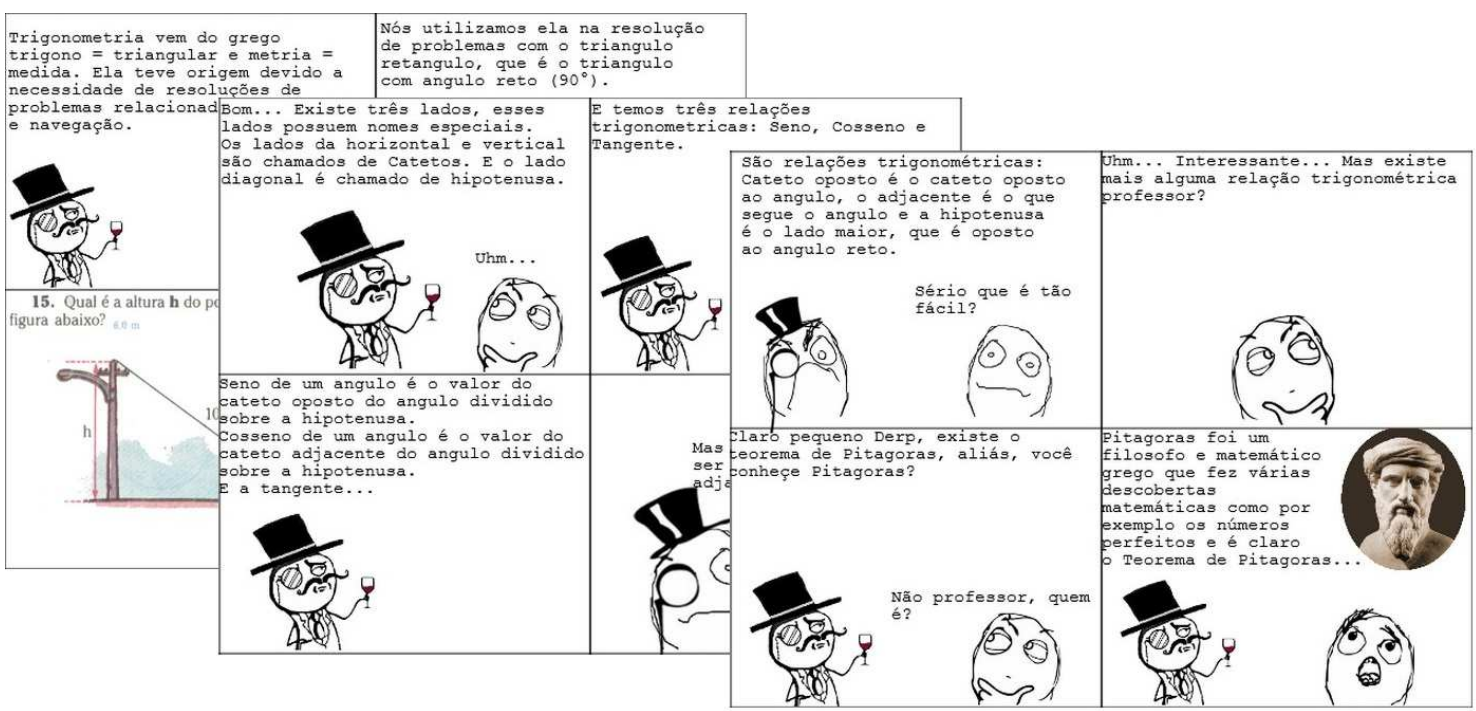

Figura 1 - Gibi Digital sobre a Trigonometria na Geometria Espacial - Meme.

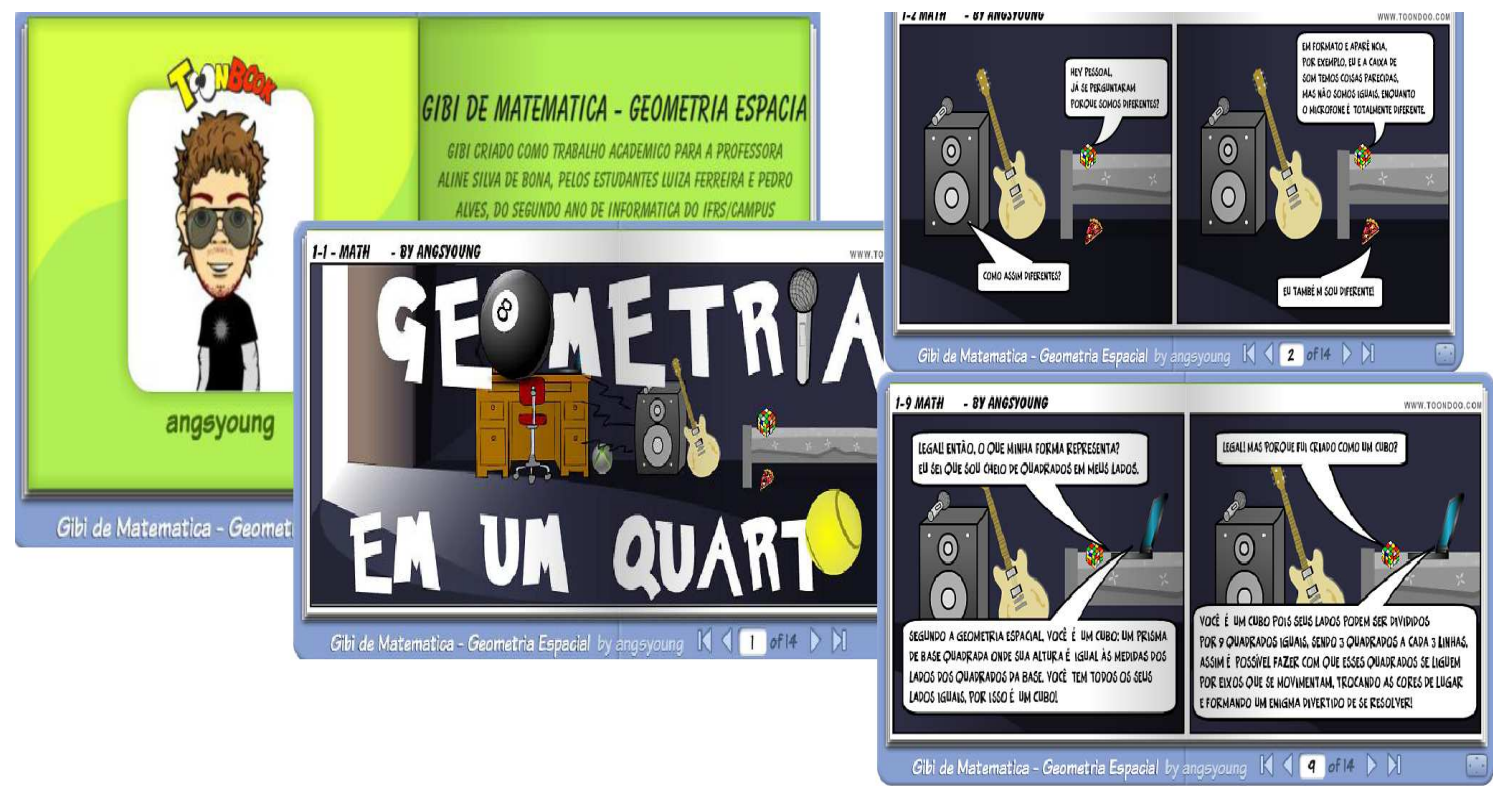

Figura 2 - Gibi de Matemática no meu Quarto com tema da Música - Tumblr. 
Todas os gibis construídos foram postados no grupo fechado no Facebook, denominado I201 - Informática, pelos estudantes e por eles discutidos os conceitos de matemática a serem explorados em cada história, assim como as tematizações escolhidas por cada trio ao criar sua história. A ação da professora de matemática foi sempre de perguntar os motivos e justificativas para cada ação, por exemplo, como no gibi selecionado para analisar com mais detalhes neste artigo a seguir: Por que é importante estudar a diagonal do cubo? Por que vocês apontam este assunto? entre outras questões. Além, da exploração curiosa de solicitar os motivos da escolha de um recurso como Memebase ao invés do HagáQuê no âmbito da matemática. O objetivo deste artigo não é discutir estas questões, mas discutir sobre a atividade em si.
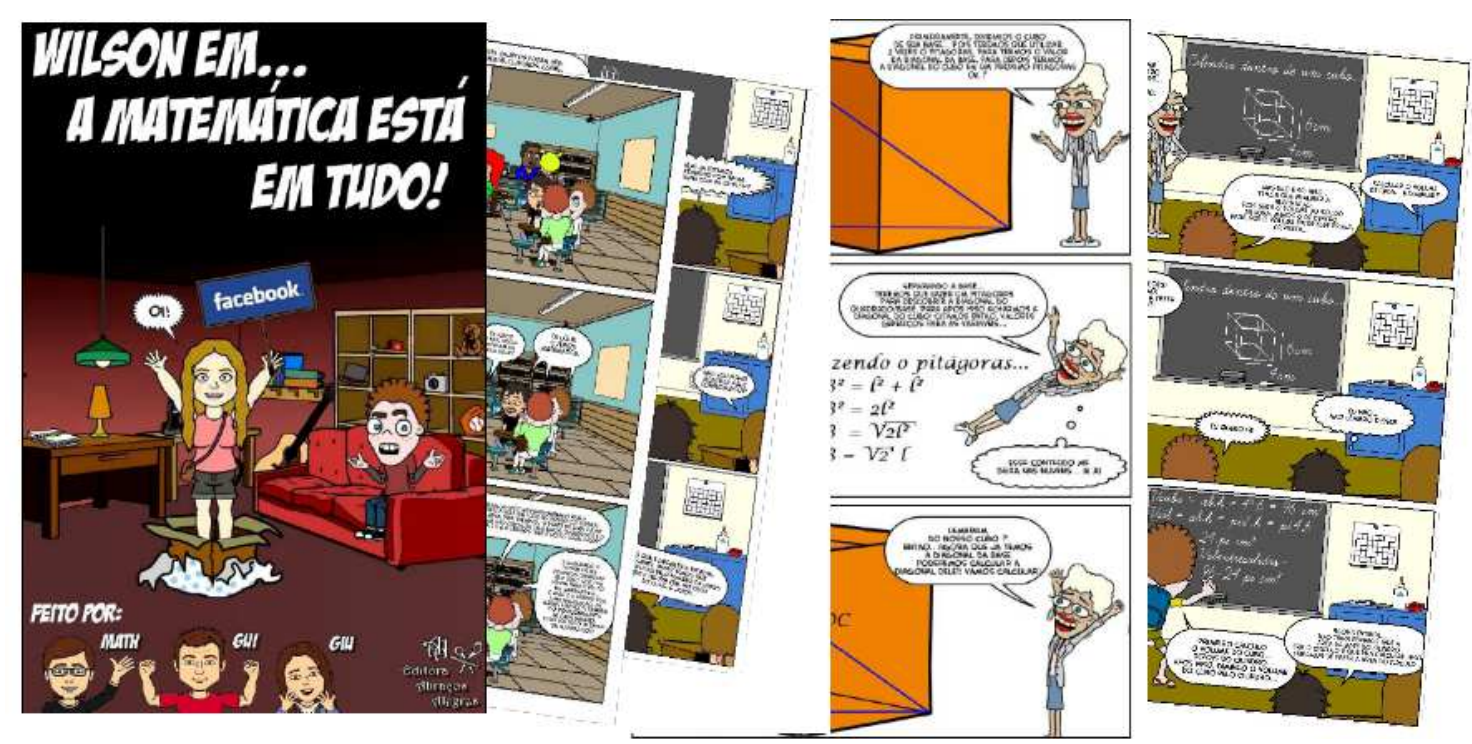

Figura 3 - Gibi de Matemática com 3 volumes - Bitstrips.

A figura 4 a seguir mostra o tutorial criado pelo trio de estudantes que construíram o gibi da figura 3. Este tutorial foi uma atividade criada pelos próprios estudantes com a finalidade de que todos aprendam diferentes recursos digitais.
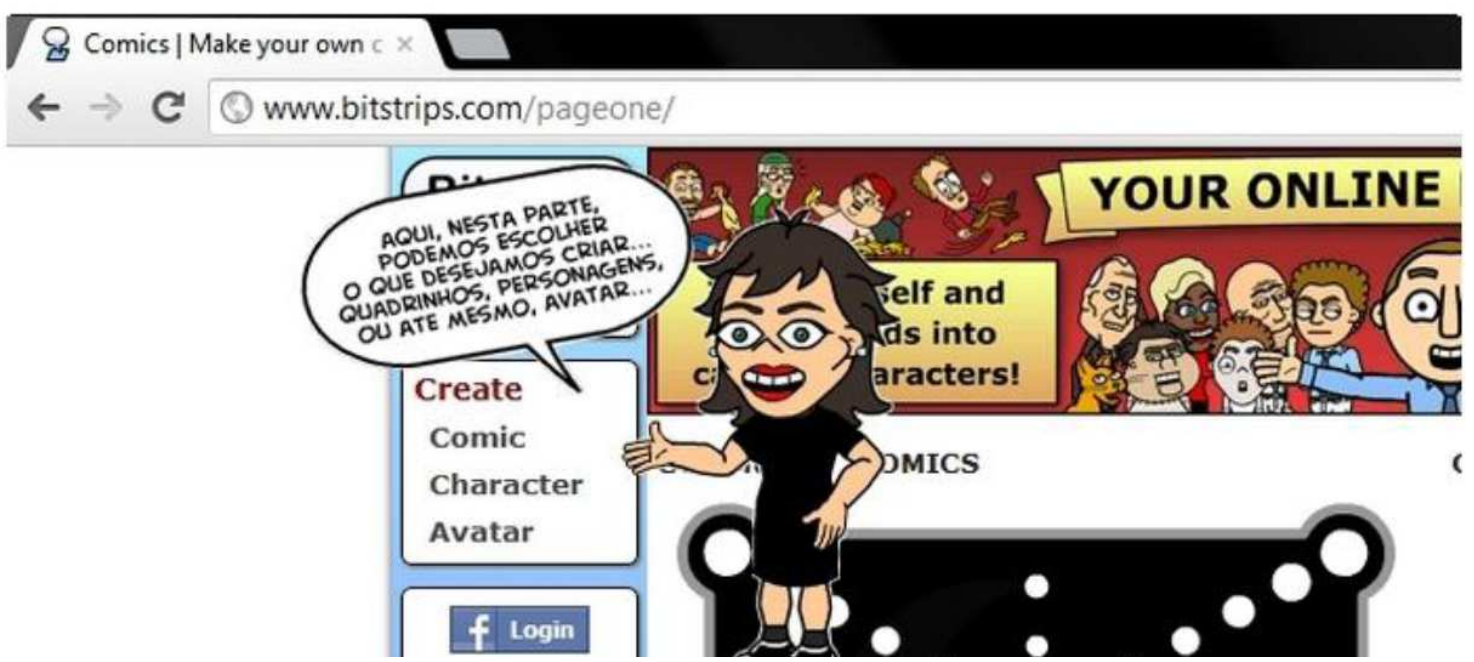

Figura 4 - Explicação dos estudantes sobre como usar o recurso digital escolhido.

Os tutoriais criados pelos estudantes demonstram muitos conceitos de 
matemática, não previstos para este ano escolar, como exemplo a proporcionalidade, que estes utilizam-se de forma natural e correta ao editarem as imagens.

Analisa-se um exemplo proposto no gibi, figura 5, que aborda um problema pesquisado por um estudante da turma em maio de 2012 e postado aos colegas para ser resolvido coletivamente no Facebook. Este problema contou com a participação de todos os 24 estudantes da turma, pois os estudantes acharam muito interessante pensar no volume "entre" os sólidos, além de observarem a integração ou acumulação ou inscrição/circunscrição (denominações dadas pelos estudantes durante a resolução no Facebook pelos estudantes de sólidos distintos como prismas, particularmente o cubo, os sólidos redondos como o cilindro.

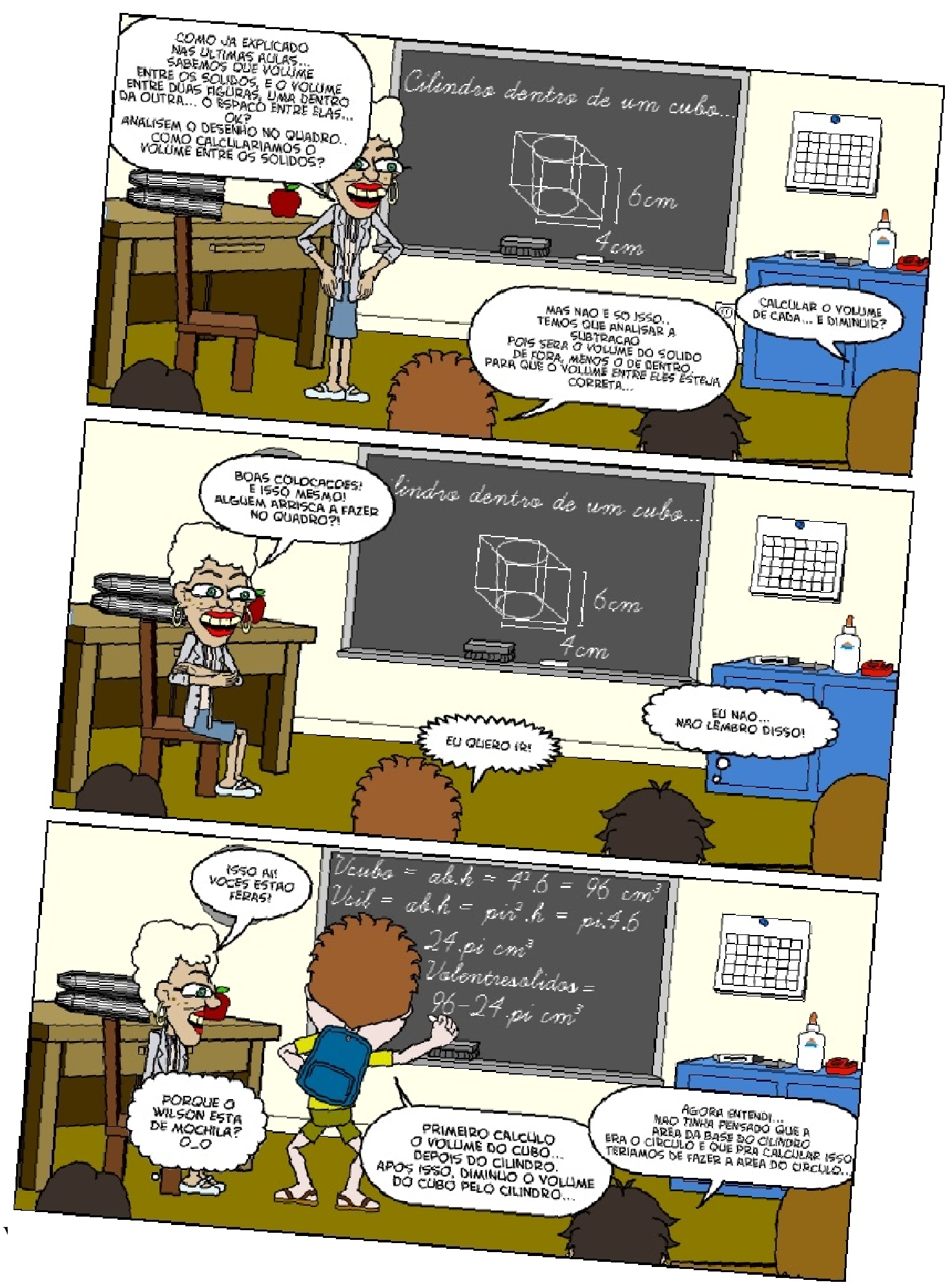


Figura 5 - Print de uma página do Gibi da Figura 3.

Importante citar que se tem o termo de consentimento dos estudantes para esta análise e não se pretende neste artigo explorar todos os aspectos nesta análise.

Ao ler apenas esta página do gibi observa-se que os estudantes entendem perfeitamente o papel docente da professora de estar sempre fazendo perguntas e preocupada com a ação dos estudantes, ou seja, que os estudantes devem resolver e partir das suas ideias. Paralelamente, o estudante que tem ideias e vai ao quadro para resolver o problema tem o apoio dos seus colegas com perguntas, sugestões e contribuições.

Depois de postados os gibis no Facebook e todos os estudantes já tinham interagido e concluído seus tutoriais a professora postou questões para todos os gibis, e uma das questões feitas a este grupo foi: Por que a professora fica olhando os estudantes resolver o problema? E algumas respostas dadas pelos componentes do grupo foram:

Math: "lógico, é sempre como sora faz....espera q a gente pesquise e resolva clo q temos na cabeça entre nos colegas..." (1)

Gui: "a gente fala a mesma língua e a sora sempre quer saber o q ja sabemos $e$ o q ela precisa propor mais atividades..." (2)

Gil: "é como a gente faz no espaço online do face...e tb escolhemos um problema $q$ um colega fez com todos p/destacar nossa sala de aula online...como a gente vê a sora na sala do face, entende?" (3)

Math: "e mais a sora tá sempre dizendo q a gente pode aprender...elogiando...e sempre temos de explicar o q pensamos...." (4)

Gui: "claro ne Math como vou te entender se vc não explicar..." (5)

Gil: " eu as vezes entendo s/explicação,mas prefiro sempre ver mais de uma forma de pensar p/ver se entendi bem....." (6)

Math: "pensando na ideia $d q$ as vezes não sabemos começar a resolver e qdo alguém começa sabemos continuar...." (7)

Gil: "e a sora ta sempre olhando tudo isso ne? se explicamos a sora sabe que a gente sabe, ne? Era isso?" (8)

Destas falas pode-se verificar que os estudantes estão apropriados do espaço de aprendizagem digital da matemática, na fala (3), por exemplo, e também da aprendizagem cooperativa. Particularmente as falas numeradas por (6), (7), e (8) são exemplos de ações cooperativas, onde a (7) é do tipo correspondência (concorda com o colega) e complementariedade (continua a resolução do colega), e as (6) e (8) são de reciprocidade (diferentes tipos de resoluções para o mesmo problema e compreende-se ambos os tipos).

Outra questão proposta pela professora ao grupo: Por que da necessidade do desenho dos sólidos para sua resolução?

Gui: "p/a gente ver o q resolver...e dai conseguir pensar em que teoria da matemática usar." (9)

Math: "eu preciso primeiro rascunhar o objeto real p/depois ver o que tem na matemática p/eu resolver o q se pede.." (10)

Gui: "isso Math se não tem representação do que devemos ver não dá p/ver qu tipo o diâmetro é o lado do cubo...e q as alturas são as mesmas...." (11)

Gil: "Só depois d imaginar o real, as vezes até manipulo objetos de verdade, consigo pensar no geral....e imaginar na cabeça os sólidos p/dai ver o q fazer e fazer 
p/variáveis genéricas como a sora sempre pergunta....".(12)

Observando estas últimas falas pode-se perceber que os estudantes precisam primeiramente de uma abstração empírica para depois desenvolver mais de uma patamar da abstração reflexionante, até a abstração refletida, quando ocorre. Piaget (1977) distingue três tipos de abstrações: empíricas, reflexivas e refletidas. A abstração empírica se apoiava sobre os objetos físicos e materiais da própria ação. A abstração reflexionante (reflexiva) aponta um salto qualitativo, quando se apresenta como a tomada de consciência pelo sujeito - a reflexão sobre reflexão, enquanto que a abstração refletida é uma abstração reflexionante com tomada de consciência. Na fala (12) a estudante demonstra a importância de se generalizar a solução do problema com variáveis, e esta conquista da modelagem matemática é um exemplo de abstração refletida.

A resposta da segunda questão dos estudantes foi construída de forma cooperativa em seus três tipos (correspondência, complementaridade e reciprocidade), e no decorrer das interações se observa as abstrações, que muito rapidamente, proporcionam entre os estudantes reflexionamentos e reflexões que permitem o progresso de patamares na abstração reflexionante.

Esta ligação entre a aprendizagem cooperativa e a abstração reflexionante é o que permite a professora de matemática analisar os desenvolvimentos das atividades dos estudantes de forma a contemplar a avaliação formativa, e nesse processo verificar a aprendizagem dos conceitos de matemática, segundo Bona, Fagundes, Basso (2012a,d), Bona, Moraes, Fagundes, Basso (2012), e Bona, Fagundes, Basso (2012c).

Importante destacar que no gibi e nas falas acima os estudantes sempre respondem preocupados em explicar o que pensam e entendem para um grupo de pessoas, não apenas responder para a professora entender, sendo esta evidencia um elemento essencial para a aprendizagem cooperativa.

A resolução do problema no gibi digital apresentada na figura 5 está correta e muito bem explicada, assim como nos 8 problemas propostos neste gibi. Os demais gibis contemplam outros problemas também resolvidos de diferentes formas pelos estudantes e todos corretos quanto ao uso dos conceitos de matemática. Foram ao todos 24 gibis construídos pelos estudantes desta turma para contemplar todo o conteúdo de geometria espacial segundo a leitura dos mesmos.

As quantificações a seguir tem a finalidade de ilustrar a compreensão dos estudantes sobre os conceitos de geometria espacial, pois a prova de matemática, com a finalidade de uma avaliação formativa e também somativa, baseada em questões de vestibular, ENEM e concursos públicos, comparada com a prova diagnóstico antes dos gibis, teve um desempenho superior de $80 \%$ nas notas e nos desenvolvimentos de forma clara e própria da compreensão de cada estudantes, pois estes escreveram com suas próprias palavras conclusões que não conseguiram explicar com símbolos matemáticos.

Depois desta avaliação a professora questiona os estudantes no Facebook sobre qual o motivo do progresso e de forma unanime todos os estudantes disseram que tanto ao construir o gibi, quanto ao ler e debater o dos colegas, estudar para prova foi apenas ler todos os gibis novamente, e "fácil, fácil....saber tudo, já que a prova foi muito mais fácil do que o problemas que nos mesmos pesquisamos e inventamos....", segundo estudante de 15 anos esta turma, que teve esta postagem curtida por toda turma em menos de uma hora.

\section{Considerações Finais}

Dentre os resultados citados anteriormente sobre esta atividades cita-se 
novamente: a escrita dos conceitos de geometria espacial de acordo com suas palavras e o destaque dados pelos estudantes aos gibis como recursos para estudar, porque estes dois elementos merecem mais estudo aos pesquisadores da área da Informática na Educação Matemática, pelo simples fato de que as tecnologias digitais online proporcionam que todas as interações dos estudantes fique registrada, de forma escrita, ou vídeo e outras mídias, possíveis de serem analisadas tanto pelo professor como pelos próprios estudantes, proporcionando a estes um recurso para estudar criado por eles mesmos. Além disso, os estudantes mobilizam-se com estas atividades diferentes como a construção do gibi desde que tenham conhecimento sobre o objetivo da atividade e de como serão avaliados. No caso deste relato, os estudantes estão inseridos num espaço de aprendizagem digital da matemática - Facebook sob uma aprendizagem cooperativa onde para todos é evidente que o processo de aprendizagem é o elemento avaliado pela professora e colegas, desta forma, realizar a atividade de matemática é um momento de aprender a aprender com criatividade e liberdade como se observa nas figuras inseridas neste artigo. Por fim, cita-se que: o método deste trabalho é parte da pesquisa-ação de doutoramento na área da Informática na Educação Matemática de um dos autores; e o trabalho do gibi analisado foi submetido pelos próprios estudantes a uma mostra de trabalhos científicos e aceito na modalidade poster como referenciado a seguir.

\section{Referencias Bibliográficas}

BONA, A.S.D.; FAGUNDES, L.C; BASSO, M.V.A. A cooperação e/ou a colaboração no Espaço de Aprendizagem Digital da Matemática. In: RENOTE - Revista Novas Tecnologias na Educação, v. 9, n. 2, 2011.

Espaço de Aprendizagem Digital da Matemática: o aprender a aprender por cooperação. In: 26 RELME - Reunião Latina Amerina de Matemática Educativa (artigo completo), Belo Horizonte, 2012a,

Redes Sociais e a Cultura Digital: um espaço cooperativo para aprender a aprender matemática. In: 26 RELME - Reunião Latina Amerina de Matemática Educativa (artigo completo), Belo Horizonte, 2012b.

Espaço de Aprendizagem Digital da Matemática: o aprender a aprender por cooperação. In: $\mathbf{2 3}^{\circ}$ SIPEMAT - Simpósio Internacional de Pesquisa em Educação Matemática (artigo completo), Fortaleza, 2012c.

Espaço de Aprendizagem Digital da Matemática: o aprender a aprender por cooperação. In: $8^{\circ}$ Salão de Ensino da Universidade Federal do Rio Grande do Sul (UFRGS) - Ciências Exatas e da Terra, Porto Alegre, 2012d.

Rede Social - FACEBOOK: um espaço de aprendizagem digital cooperativo. In: $\overline{8}^{\circ}$ Salão de Ensino da Universidade Federal do Rio Grande do Sul (UFRGS) Ciências Humanas, Porto Alegre, 2012e.

BONA,A.S.D.; MORAES, A.; BASSO, M.V.A.; FAGUNDES, L.C. Cultura Digital e Aprendizagem Cooperativa. In: RENOTE - Revista Novas Tecnologias na Educação, v.10, n.1, 2012.

FIORENTINI, D.; LORENZATO, S. Investigação em educação matemática: percursos teóricos e metodológicos. Coleção Formação de Professores. Campinas: Autores Associados, 2007.

PETERS, O. A educação à distância em transição. São Leopoldo: Unisinos, 2009.

PIAGET, J. Estudos Sociológicos. Rio de Janeiro: Forense, 1973.

Abstração Reflexionante: Relações lógico-aritméticas e ordem das relações 
espaciais. Porto Alegre: Artmed, 1977.

SILVA, G. P.; DEMCZUK, M.L.; RAMOS, G. S.; BONA, A.S.D. Gibi da Geometria Espacial. In: $\mathbf{2}^{\mathbf{a}}$ Mostra do IFRS - Restinga. Porto Alegre, 2012. 